He shows evidence of severe peripheral neuritis affecting both legs with marked wasting of the calves and absent sensation to pin-prick and cotton wool over the feet and legs. Plantar flexion and dorsiflexion at the left ankle are completely lost, and the interphalangeal joint of the left great toe is destroyed by neuropathic arthropathy. His feet are extremely painful and he has iroublesome trophic ulcers. In addition he has gross impairment of muscle power in the proximal muscle groups of the lower limbs. ${ }^{1}$

This case would appear to be a further example of peripheral neuropathy and myopathy associated with pituitary growth hormone excess. - I am, etc.,

County Hospital,

Castlebar

Mastalgia, F. L., Barwick, D. D., and Hall, R.,
Lancet, 1970, 2, 907.

\section{Amantadine-induced Aggressiveness}

SIR,-The antiparkinsonian effect of amantadine was shown in 1969 by Schwab ${ }^{1}$ and since then confirmed by several other authors. ${ }^{2}$ The behavioural and biochemical effects of this drug in experimental animals suggested to Vale et al..$^{4}$ the possibility of using it as an antidepressant; a positive effect was claimed by them in depressed patients.

On the basis of this finding, we have treated four aged depressed patients with amantadine for at least three weeks. The dose regimen was started with $100 \mathrm{mg} /$ day and then slowly increased to $300 \mathrm{mg} /$ day within 10 days.

We did not observe any positive effect on mood but, conversely, noticed a progressive increase of motor restlessness, anxiety, and sudden bursts of violent, aggressive behaviour, with hostile attacks upon the ward's staff. The hostility and aggressiveness became evident usually afte 10-15 days of treatment, when amantadine plasma levels were about $800 \mathrm{ng} / \mathrm{ml}$, and tended to disappear within 4-6 days after discontinuation of treatment. A detailed description of these results will be published later.

Since we could not find any data in the literature on amantadine-induced aggressive behaviour in depressed patients during observations have been made by others.

The appearance of aggressive and hostile behaviour in depressed patients during amantadine treatment is also of particular interest in view of a similar phenomenon recently observed by Goodwin et al. ${ }^{5}$ in depressed patients treated with high doses of L-dopa. The same authors suggest that the aggressiveness seen in humans after L-dopa may be related to an increased catecholamine synthesis. Considering the similarity between the antiparkinsonian and pharmacological effects of L-dopa and amantadine, it is possible to hypothesize the existence of an analogous mechanism to explain the clinical results obtained with our patients. -We are, etc.,

M. Rizzo P. L. MORSELI Psychiatric Provincial Hospital "P. Pini,"

Instituto di R:cerche Farmacologiche "Mario Negri," Milan, Italy

1 Schwab, R. S., England, A. C. Inr., Poskanzer D. C., and Young, R. R., Journal of the 2 Parkes, J. D., Zilkha, K. J., Calver, D. M., and
Knill-Jones, R. P., Lancet, 1970, 1, 259.
3 Fibiger, H. C., Fox, M., McGeer, E. G., and
McGeer, P.' Loumal of Pharmacy and Pharmacology $1971,23,724$ of

4 Vale, S., Espeiel, M. A., and Dominiguez, J. C., Lance, 1971, 2, 437.

Goodwin, F. K., Murphy, D. L., Brodie, H. KK.,
and Bunney, W. E., Biological Psychiatry, 1970, 2,341 .

\section{Varieties of Smoke}

SIR,-I recently re-read your leading article (18 September 1971, p. 656) which questions the value of tar assays. The views expressed were somewhat disturbing and persuade me to raise several points.

(1) Measurement of the tar delivered at the proximal end of the butt by a particular brand of cigarette is a simple, reliable procedure. ${ }^{1}$ It is used in America, Canada, and Australia-at least by the tobacco industry and by private or public health organizations. Interpretation is also simple-a cigarette delivers so many milligrams of tar to the smoker's lips if smoked in standard fashion. From tests performed in the chemistry department at Monash University a smoker's "tar table" has been produced. and from it comparison between brands is possible.

As you say, smoking habits vary, but a packet of Australian cigarettes near the top of this table delivers $100 \mathrm{mg}$ of tar and $6 \mathrm{mg}$ of nicotine; a packet of cigarettes from the bottom of the table delivers $520 \mathrm{mg}$ of tar and $32 \mathrm{mg}$ of nicotine. These are gross differences. The fact that more frequent puffing may occur could hardly make up a five-fold difference in tar and nicotine delivery.

(2) The smoking dogs of Hammond and Auerbach ${ }^{2}$ demonstrated that lung damage is related quite directly to regular tar intake. Mortality rates in filter smokers, as recorded by Bross. ${ }^{3}$ suggest the same.

If low-tar cigarettes were available on the British market (you will only find them by testing), some smokers who used them would notice diminution of cough and return of taste (personal observation)

(3) The people who are going to die soon from smoking are the addicts of 20,30 , or 40 years. If they cannot give up, they can smoke pipes, cigars or low-tar cigarettes and thereby lower their risk. We should not abandon the present generation of breadwinners. None of this suggests low-tar cigarettes are "safe," they are merely less risky.

(4) It is not difficult to differentiate between relative risks in a public campaign. It has been done in the U.S.A. and Canada, and our own experience in the State of Victoria is also of some interest.

We can reasonably claim to have generated a demand for low-tar cigarettes among addicted smokers over the past three years. Since per capita cigarette consumption has not changed much, this is presumed to be at the expense of high-tar brands. We have seen no signs that this campaign has encouraged or unduly reassured smokers, although some have worked down the ladder and eventually given up. Two low-tar brands are now among the more heavily promoted brands in this State. (The tobacco industry is not notably responsive to pressure of public health opinion, but is acutely sensitive to the demands of the market). I think this campaign is a useful gesture to the smoker with a high and immediate risk. It need not detract from the overall anti-smoking message.
If your editorial advice is taken, you will never see low-tar cigarettes on the market, never discover the benefit of this to the coughing, tasteless smoker, and never gain material for the necessary epidemiological study which is needed to determine just how much a lower daily tar intake lowers smoking risk.-I am, etc.,

Anti-cancer Council of Victoria,

Nigel GRAY East Melbourne,
Victoria, Australia

1 Moore, G. E., Bross, I., Shamberger, R., and Bock, F. G., Cancer, 1967, 20, 323., R.,
Hammond, E. C., et al., Archives of Environn.ental Health, $1970,21,740$.
Bross, I. D. J., and Gibson, R., American Boss, I. D. J., and Gibson, R., Americ
four Public Health, 1968, 58, 1396.

\section{Presenile Dementia}

SIR,-Unfortunately, the facts presented in our paper (29 April, p. 249) do not help to answer many of the questions posed by your correspondents.

The mean age of the 106 patients investigated for presumed dementia was 61 years; the youngest was aged 34, and the oldest was aged 78. The outcome of investigation in relation to the age at which it was carried out is shown below.

\begin{tabular}{|c|c|c|c|c|}
\hline Age $\quad . . \quad \ldots$ & $<50$ & |50-59 & $60-69 !$ & $70+$ \\
\hline No. of patients & 8 & 40 & 43 & 15 \\
\hline $\begin{array}{l}\text { Not demented } \\
\text { (uncertain in parentheses) }\end{array}$ & $3(2)$ & $7(3)$ & $3(2)$ & 2 \\
\hline $\begin{array}{l}\text { Diagnosis of Dementia } \\
\text { Space occupying mass }\end{array}$ & & 2 & 5 & 1 \\
\hline Arteriosclerotic & & 1 & 5 & 2 \\
\hline Alcoholic .. & & 4 & 2 & \\
\hline $\begin{array}{c}\text { Normal pressure } \\
\text { hydrocephalus }\end{array}$ & & 1 & 3 & 1 \\
\hline $\begin{array}{ccc}\text { Creutzfeldt } & - & \text { Jakob } \\
\text { disease } & . . & . .\end{array}$ & & 1 & 1 & 1 \\
\hline Huntington's chorea & 2 & 1 & & \\
\hline $\begin{array}{c}\text { Post - traumatic cere- } \\
\text { bral atrophy }\end{array}$ & & 1 & & \\
\hline $\begin{array}{l}\text { Postsubarachnoid } \\
\text { haemorrhage }\end{array}$ & 1 & & & \\
\hline Limbic encephalitis & & & 1 & \\
\hline Cerebral atrophy .. & & 19 & 21 & 8 \\
\hline
\end{tabular}

Our data do not help define "an age criterion" for selection of demented patients for full investigation asked for by Dr. P. K. Bridges (20 May, p. 465). This decision remains a matter of judgement in which chronological age is one of many factors taken into consideration. For this reason the term "presenile" (which has no age definition) was used for it conveys the same concept of biological age as does the indefinable term adult life.

To answer Dr. H. M. Hodkinson (13 May, p. 404) on "the value of neurological investigation at any given age in middle life" would require a much larger number of patients, and to complete the picture one would wish to know the cause of dementia in those elderly patients who are not fully investigated in life.

Dr. Hodkinson also asks for further information on those patients who were judged to be amenable to (that is, capable of) treatment. We felt it would be useful to give some conservative estimate, and the $15 \%$ figure quoted included the three patients with benign intracranial tumours, 
the patient with clear-cut communicating hydrocephalus, the patient with epilepsy, the two patients intoxicated by drugs, the eigh depressed patients, and the patient with mania. If we had wished to press the point we might have included 24 other patients in whom the results of investigation could have led to some attempt to treat the patients or their relatives; that is, treatmen for the seven hypertensive patients with arteriosclerotic dementia, treatment for the six alcoholics, genetic counselling for the relatives of three patients with Huntington's chorea, symptomatic therapy for the five patients with malignant brain tumours, and even experimental antiviral treatment for the three patients with Creutzfeldt-Jacob's disease.-We are, etc.,

C. D. MARSDEN

Department of Neurology

Institute of Psychiatuy and

King's Colhege Hospital Medical School,

London S.E.S

M. J. G. HARRISON

National Hospital for Nervous Diseases,

London W.C.1

\section{Abortion and Miscarriage}

SIR,-It is surely time that we abandoned the term "abortion" as a synonym for the lay term "miscarrage." And this for two reasons. First, while it is the function of language to impart information, I find I no longer know what it means when general practitioner writes to me that his patient had an abortion last year. As a result I have the embarrassing task of having to ask the patient whether this was an accident that she bitterly regrets, or whether this was a procedure she requested. The second reason is that patients are objecting even more strongly than ever to the appearance of the word "abortion" in the obstetric history part of their antenatal notes. Years ago it was easy to explain that this was merely a medical term for what they called a miscarriage, but of course this explanation is no longer acceptable.

I suggest, therefore, that as a profession we employ the word "miscarriage" in cases where the pregnancy was lost without the known intervention of a helping hand, and "termination of pregnancy" for procedures carried out under the Abortion Act.-I am, etc.,

Thorpe Maternity Hospital

R. F. R. GARDNER

Peterlee, Co. Durham

\section{Epitaph for the M.C.H.C.}

SiR,-The mean corpuscular haemoglobin concentration (M.C.H.C.) obtained from the Coulter " $S$ " machine is not a good index of iron deficiency (16 October 1971, p. 169), but I have found it useful in evaluating the quality of results produced by the machine. A simple calculation based on the definitions of the indices shows that M.C.H.C. $\equiv \frac{\text { M.C.H }}{\text { M.C.V. }}$

Thus, if either the M.C.H. (mean corpuscular haemoglobin) or the M.C.V. (mean corpuscular volume) is inaccurate the M.C.H.C. will tend to depart from the expected range.

Even highly reliable instruments do occasionally become inaccurate and in times of difficulty the $\mathrm{Hb}$ and R.B.C. (hence M.C.H.) results can be checked on other types of instrument. There is no way of checking the M.C.V. because the microhaematocrit obtained manually is different from the Coulter " $S$ " result.

When the M.C.V. standardization, measurement, or calculation is suspect, in spite of correct " $4 \mathrm{C}$ " results, and a series of specimens shows good correlation for $\mathrm{Hb}$ and R.B.C. between the Coulter " $S$ " and other methods, a glance at the M.C.H.C. allows one to judge whether an abnormal M.C.V. is genuine.

\begin{tabular}{c|c|c|c|c|c}
\hline M.C.V. & $\begin{array}{c}\text { False } \\
\text { Low }\end{array}$ & $\begin{array}{c}\text { True } \\
\text { Low }\end{array}$ & $\begin{array}{c}\text { True } \\
\text { Normal }\end{array}$ & $\begin{array}{c}\text { True } \\
\text { High }\end{array}$ & $\begin{array}{c}\text { False } \\
\text { High }\end{array}$ \\
\hline M.C.H.C. & High & Normal & Normal & Normal & Low
\end{tabular}

The M.C.H.C. is a useful addition to the other methods of quality control which are being used.-I am, etc.,

Robert J. Crawford

Department of Haematology,

Southern General Hospital,

Glasgow

Pancreatin as a Source of Hospital-acquired Salmonellosis

SIR,-We noted with concern the report on the presence of salmonella in pancreatin made by vacuum drying and extraction with a fat solvent (13 May, p. 376). We were not particularly surprised, for these organisms are still far too common on animal carcasses, and vacuum drying provides a not unfavourable environment for multiplication. Surface sterilization is undoubtedly a step in the right direction, but we doubt whether it can be as effective as the alcohol sterilization technique we use routinely in the preparation of all our pancreatin. (Pat. Appn. 30600/69.)

The result of applying our standard manufacturing process to highly contaminated raw material in the laboratory was as follows:

\begin{tabular}{lc}
\hline \multicolumn{2}{c}{ Before Stage 2* } \\
$\left.\begin{array}{lc}\text { Coliforms } & 7 \times 10^{4} \\
\text { Streptococci } & 3 \times 10^{4} \\
\begin{array}{l}\text { E. coli } \\
\text { Pseudomonas }\end{array} & >1 / g \times 10^{4}\end{array}\right\}$ & After Stage 2 \\
\hline
\end{tabular}

(*Stage 2 is treatment of the homogenized pancreas with alcohol).

We consider that pancreatin manufactured by this process could present no danger to health from the presence of salmonellae. Tests on $25 \mathrm{~g}$ samples of thousands of batches confirm our opinion, for we have never once detected salmonellae.-We are, etc.,

H. F. Frost Director of Research

G. FARKAS Chief Bacteriologist,
Weddell Pharmaceuticals Ltd.

London E.C.1

\section{Controlled Drinking for Alcoholism}

SIR,-Dr. S. Rachman (3 June, p. 591) misses the point. Relapse is not just a "bout of excessive drinking;" this is merely the overt expression of the relapse process. The actual relapse precedes the bout of drinking and is in fact the decision to start drinking. This has been confirmed experimentally and confirmed clinically by the fact that patients taking disulfiram (Antabuse) who relapse stop taking their disulfiram two or three days before starting to drink. If behaviour therapy is to be considered, since it is apparently easier to abstain than to control drinking, then behaviour therapy should be directed to strengthen abstention rather than to monitor controlled drinking. Abstinent alcoholics who have had many relapses will tell you that it is in fact easier not to take the first drink than to stop drinking after one or two drinks.

While I agree with the implication that total abstention need not be the entire goal in the treatment of alcoholics, in our present state of knowledge abstention should still be part of the advice we offer to our alcoholic patients.

The observations of Davies ${ }^{2}$ that some alcoholics are capable of returning to a life of social drinking may be based on the explanation that this group of alcoholics are basically suffering from depression. At the alcoholic unit in this hospital we are investigating this possibility by studying the distribution of body potassium in alcoholics and also by a controlled trial of the effects of lithium carbonate on the relapse rate of alcoholics who have a definite history of depression. It may be that the Davies' cohort were alcoholic patients who have had depressive illnesses, but when in remission no longer need to drink alcohol as an attempt at self-medication, but can once again use alcohol socially.-I am, etc.,

West Park Hospital,

JULIUS MERRY Epsom, Surrey

1 Merry, J., Lancet, 1966, 1, 1257.
2 Davies, .D. L., Quarterly fournal of Studies on
Alcoholism, 1962, 23, 94.

\section{Donors for Organ Grafting}

SIR,-Dr. E. Poole (6 May, p. 350) does not like our definition of "irreversible brain damage" (1 April, p. 48). The latter referred to a paper which has since appeared in the Solicitors' fournal (28 April), in which it is made quite clear that the brain damage combined with unconsciousness was both prolonged and widespread. Our full consideration would clearly preclude such conditions as cerebral thromboses and cerebral abscesses, from which improvement normally occurs. We think that this point is quite clear in our full length paper.-We are, etc.,

HaRold HillmaN

Unity Laboratory,

Department of Biological Sciences,

University of Surrey

London E.C.4

T. M. AldRIDge

\section{Severe Toxaemia of Pregnancy}

SIR,-Dr. J. E. F. Pohl and others are to be congratulated on their successful management of four cases of severe toxaemia (3 June, p. 568). However, their presentation is unduly flattering to the diazoxide used in management, and probably pays insufficient tribute to the quality of the monitoring of the fetal condition, which in all the cases appears to have been assessed mainly by the measurement of fetal growth.

In my experience when "hypertension complicates pregnancy and proves resistant 